\title{
Second Graders’ Recycled/Craft Item Products Demonstrate Life Cycle Content Knowledge and Creativity Skills
}

\author{
Angela Naomi Webb, Audrey C. Rule \\ Department of Curriculum and Instruction, University of Northern Iowa, Cedar Falls, USA \\ Email: awebb82@uni.edu
}

Received June $1^{\text {st }}$, 2012; revised July $12^{\text {th }}$, 2012; accepted July $19^{\text {th }}, 2012$

\begin{abstract}
Creativity is a necessary skill for students to become problem solvers in the rapidly changing $21^{\text {st }}$ century. This study's main activity allowed students to demonstrate their content knowledge in an engaging way while also exhibiting creative strengths. Twenty-two second grade students (15 female, 7 male) of mixed ability levels at a Title 1 school produced projects using identical sets of recycled and craft items. They incorporated vocabulary words and images associated with the life cycles of four organisms: horse, dragonfly, sea turtle, and bean plant. Projects were analyzed for creative strengths as well as science concept integration. Student-made products showed vocabulary from all four life cycles, but familiar organisms (dragonfly and bean plant) were depicted more frequently. Creative strengths evidenced in student work included: elaboration, breaking boundaries, storytelling articulateness, originality, and emotional expressiveness, among others. The authors recommend teachers incorporate similar creative tasks as assessments of content learning. Additional studies integrating more creative product assessments for a longer duration to show growth over time are suggested.
\end{abstract}

Keywords: Life Cycle; Science; Second Grade; Creativity

\section{Introduction}

The high stakes testing climate of the No Child Left Behind legislation for most schools has caused teachers to focus on content addressed by standardized assessments through teacher-led instruction and to narrow the curriculum to tested subjects, thereby reducing the arts and more creative activities (Center on Education Policy, 2009). A Rand study (Hamilton, Stecher, Marsh, McCombs, Robyn, Russell, Naftel, \& Bamey, 2007) reported that teachers expressed concern for high-achieving and creative students who received less attention because the curriculum was restricted and attention focused more on low achievers. This study examined how a highly creative activity can be used as a practice and assessment of student vocabulary and concept learning for a second grade unit on animal and plant life cycles.

\section{Support for $21^{\text {st }}$ Century Skills}

Various educational groups promoting “21 $21^{\text {st }}$ Century” skill programs highlight creativity and problem solving skills as vital to preparing for a changing, highly-technological, global workplace. A group of international researchers (Assessment \& Teaching of $21^{\text {st }}$ Century Skills, 2012) identified essential skills for success in the future in four areas: ways of thinking-creatively and critically, ways of working with others through communication and collaboration, tools for working-information literacy and communication technology, and citizenship and responsibility skills for living in the world. Both the Partnership for $21^{\text {st }}$ Century Skills (2011) and the Center for $21^{\text {st }}$ Century Skills (Education Connection, 2012) include creativity, innovation, and problem-solving skills as thinking skills critical to success in a quickly evolving, complex society. The creative problem solving activity described in this article can support these skills while also serving as a way for students to evidence the content knowledge they are acquiring.

The activity on which this article focuses was used as a creative practice and assessment of content knowledge during a culminating activity for an animal and plant life cycle unit of instruction. These second graders had been reading about the life cycles of the sea turtle (egg-hatchling — adult), bean plant (seed-sprout—seedling-flowering plant), horse (stallion and mare-offspring - colt or foal), and dragonfly (egg - larvanymph-adult dragonfly) and had been practicing these concepts in creative ways by converting simple figures and squiggles into images related to the life cycles and standard ways by drawing the stages of the organism's life cycle. See Webb and Rule for detailed explanation of that activity (2012). As a final in-class assignment combining all four organisms' life cycles, students were each given an identical set of recycled and craft items, a piece of construction paper of their color choice as a base on which to make and label the parts of the product, and asked to use all materials in making a construction that showed as much as they could about the life cycles. Table 1 shows the list of items in the identical sets given to students.

Figure 1 shows a representative second grader's final product. This student has shown three of the four life cycles in her product. A dragonfly was depicted by the black foam cutout. The pink fuzzy chenille pieces are dragonfly nymphs. The wooden clothespin is a hovering dragonfly ("hover" was a targeted vocabulary word). The egg carton compartments with paper punches are the bean plant seeds. The green palm tree stirrer is a bean plant sprout emerging from the soil. The plastic cup represents the carapace of a sea turtle as it digs a hole to lay eggs. The eggs are shown as the white marbles in the project. Most student products addressed two or three organism life 
Table 1.

Set of materials given to each second grade student.

Set of Given Items
Pink fuzzy bumpy chenille stick (pipe-cleaner)
30 cm of inch-wide peach grosgrain ribbon
Green plastic palm tree drink stirrer
Clear plastic cup
Wooden clip type clothespin
Wooden tongue depressor
Black foam block
Three silver stars on a string
3 white flat glass marbles
Red spattered cardboard frozen food tray
$13 \times 15$ cm red heart netting
$13 \times 20$ cm buff cardstock
$18 \times 8$ cm white envelope with spoonful of multicolored confetti paper
punches inside
2 sections of a gray cardboard egg carton
Apple and star stickers
2 black plastic drink stirrers

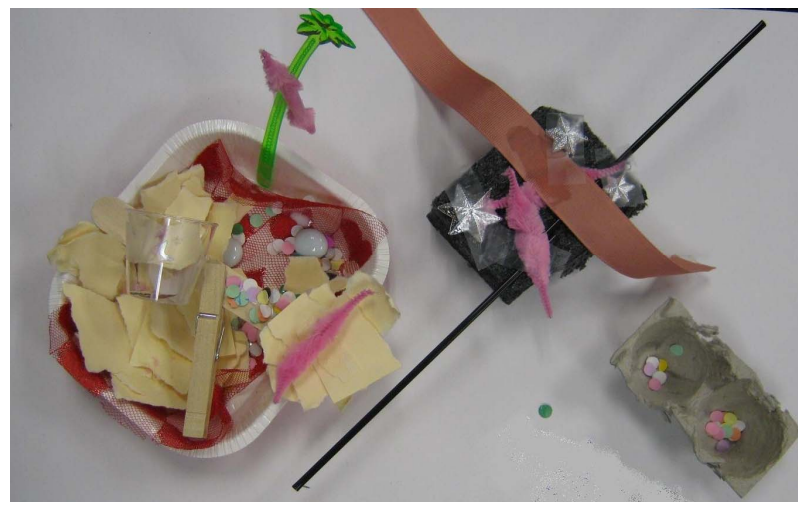

Figure 1.

Example entire life cycle product made by second grade student.

cycle components, in a similar manner to this student's work.

\section{Creative Transformations}

J. P. Guilford, renowned psychologist, was an early researcher recognizing that intelligence was a multidimensional construct. He developed a model of mental functioning called the Structure of the Intellect (Guilford, 1967; Guilford \& Hoepner, 1971). Although this model is no longer an accepted model of cognitive functioning, it brought to light many important aspects of creative production such as the distinction between convergent (seeking to zero-in on the one correct answer) and divergent (seeking many, varied correct answers) production. The model also highlighted the diverse mental processes in which humans can engage; these processes remain valid even if Guilford's conception of how the brain operates was faulty. The Structure of the Intellect model was shown figuratively as a cube with three different dimensions: operations (general intellectual processes), content (broad areas of information), and products (the result of applying mental operations to content). Products included units, classes, relations, systems, implications, and transformations. This last type, transformation, can be applied to the student products made in this study.

"A transformation is any kind of change in information" (Guilford, 1977: p. 37). Guilford highlighted certain transformations as particularly important. Figural transformations involved a change in the spatial orientation of a figure or a new image produced from a figure by the addition of lines, shapes, or shading. In this study, the creative constructions were a type of figural transformation because the given objects were cut apart, bent, rearranged, and glued to make a new construction related to life cycles. Semantic transformations refer to a substitution of meaning. An object used in an unusual way that is counter to its typical recognized purpose, such as using a ruler to poke an object out from beneath a bookcase, rather than measure, is an example. As students examined the given set of objects for their creative construction, they needed to repurpose the recycled items as parts of their life cycle constructions, rather than their original use as food trays, drink stirrers, or egg cartons. This re-visioning of purpose was a semantic transformation.

Transformation, though not always referred to with this term, is still recognized as an important mental process resulting in creative products. Michael Michalko (2001), organizer of a team of NATO intelligence specialists and academics who inventoried all known creative thinking methods to provide a storehouse of techniques for solving international problems, called transformation recognizing "latent potential” (p. 234). He stated, "[E]very new subject or idea produces a host of creative byproducts, initially seen as irrelevant, but available for fashioning into novel new directions" (p. 234). Michalko gave an example of how people in Nairobi saw the latent potential of old tires, recycling them into sandals as they recognized the durability of the material and made a functional shift-a semantic transformation in Guilford's terminology.

More recently, Davis, Rimm and Siegle (2011: p. 211) defined transformation as the "ability to adapt something to a new use; see new meanings, implications, and applications; or creatively change one object or idea into another”. They concluded, "Transformation is an extremely important creative ability.”

\section{Previous Work}

The creative problem solving activity used in this study has been described in only a few previously published works. Rule, Zhbanova, Hileman Webb, Evans, Schneider, Parpucu, Logan, Van Meeteren, Alkouri, and Ruan (2011) conducted two similar workshops at a state conference for education of the gifted using this problem-solving activity. Participants, who were mostly teachers of the gifted, were each given an identical set of materials - in one workshop, the set was identical to that used in the current study. Teachers in that workshop were asked to make something that related to an interpretation of the theme "cool space”. The other workshop participants were given a different set of materials and the theme "under water". The products made by participants and an analysis of the creative strengths shown are provided in this document. 
Another trial of this problem solving activity is described in an article by Rule, Alkouri, Criswell, Evans, Hileman Webb, Parpucu, Ruan, Van Meeteren, Uhlenberg, Vasileva, and Zhbanova (in press). Participants in this study were mostly graduate students in a creativity course who made products from identical sets of materials that conformed to various constraints. After making the products, students were told to revision each by relating it to a topic in economics as practice in re-visiting the problem and keeping it open. The journal article explains how this activity may be used to infuse creativity into social studies education.

The current study extends this technique to K-12 education by having second graders apply the method to a unit on life cycles. The following section describes the details of the method and is followed by the results and conclusions of the study.

\section{Method}

This study was conducted with a class of 22 second grade students learning about four different animal and plant life cycles. The focus was learning science concepts and vocabulary through reading of nonfiction texts at the students' reading levels. The study sought to examine how a creative task in which students made a life cycle construction of a given set of recycled and craft materials could be used as a content assessment.

\section{Participants}

Twenty-two students (7 male, 15 female; 19 Caucasian, 3 African-American, 1 Hispanic) of mixed academic performance comprising an intact second grade classroom at a public school in rural Iowa participated in the study. This school's population was low socio-economic status with fifty-seven percent of children at the school receiving free or reduced cost lunches. This study was approved by the overseeing university's Human Subjects Committee (HP\#11-068), the district's superintendent, the school's principal, and with written consent from parents and participating students.

\section{Design}

The life cycles of four organisms were investigated over a month with one week devoted to each organism. Key vocabulary words were identified for each animal or plant life cycle. These were practiced by making creative figural transformations on paper (sea turtle and bean plant) or by drawing and labeling the life cycles (dragonfly and horse). Another study (Webb \& Rule, 2012) reported on the vocabulary test advantage for practicing creatively with figural transformations. In contrast, this study examined a culminating activity for the life cycle unit, making a three-dimensional construction of a given set of recycled and craft materials.

For a final assessment of student learning of life cycle concepts, each student was given an identical set of recycled and craft materials as listed in Table 1. These materials showed a variety of physical properties such as flexibility, stiffness, color, shape, volume, and texture. This set was identical to a set used in an earlier experiment with a different content theme ("cool space”) conducted with adult participants attending a gifted education conference (Rule et al., 2011). Students were told the following guidelines for the activity: 1) all of the given items should be incorporated into the final structure; 2) the theme for the construction is the four life cycles recently studied (sea turtle, dragonfly, horse, bean plant); 3) students were asked to identify key vocabulary in their products; 4) a thirty-minute time limit was given; 5) students were allowed to cut, color, or fold items and use tape, glue, crayons, and markers; 6) students were allowed to choose a piece or two of colored construction paper as a base for their work. The student products were photographed and students wrote labels or descriptions of what they had depicted.

\section{Data Analysis}

The number of key vocabulary words studied for each of the four organisms was tabulated. The products were examined for creative strengths and techniques.

\section{Results and Discussion}

\section{Creative Strengths}

Table 2 shows creative strengths exhibited by second graders' products. This list is not exhaustive of all possibilities, but shows those expressly taught in previous lessons by the teacher (originality, elaboration, emotional expressiveness, and breaking boundaries), along with others spontaneously shown by the students in their products. Torrance, Ball, and Safter (1992), besides identifying and scoring fluency, flexibility, originality, elaboration, and abstractness of titles in the Torrance Test of Creative Thinking (figural format), identified several other "creative strengths" that test subjects might exhibit in their work. These included the other ideas presented in Table 2 such as storytelling articulateness, movement or action, and emotional expressiveness, among others.

Table 3 shows the identified vocabulary words students incorporated into their structures. Students used more vocabulary related to bean plants and dragonflies than sea turtles and horses. Because students had grown a bean plant, were familiar

Table 2.

Creative strengths evidenced in the study.

\begin{tabular}{|c|c|}
\hline Creative Strength & Explanation \\
\hline Originality & Different idea not previously represented. \\
\hline Elaboration & Adding extra details to the illustration. \\
\hline $\begin{array}{l}\text { Emotional } \\
\text { Expressiveness }\end{array}$ & $\begin{array}{l}\text { Emotional words or facial expressions on the } \\
\text { animal depictions. }\end{array}$ \\
\hline $\begin{array}{l}\text { Storytelling } \\
\text { Articulateness }\end{array}$ & Sense of a story or sequence of events. \\
\hline Movement/Action & Motion lines or action. \\
\hline Breaking Boundaries & $\begin{array}{l}\text { Turning upside-down or breaking normal } \\
\text { lines and boundaries. }\end{array}$ \\
\hline Abstract Ideas & $\begin{array}{l}\text { Ecological or political messages integrated in } \\
\text { the project. }\end{array}$ \\
\hline Three-Dimensionality & $\begin{array}{l}\text { Instead of spreading the items into a flat } \\
\text { object, the object has height. }\end{array}$ \\
\hline Internal Visualization & $\begin{array}{l}\text { Showing what is inside with a cutaway or } \\
\text { transparent piece. }\end{array}$ \\
\hline Richness of Imagery & $\begin{array}{l}\text { Artistic appeal: Particularly cute or beautiful } \\
\text { work. }\end{array}$ \\
\hline
\end{tabular}


Table 3.

Vocabulary addressed by the three-dimensional life cycle creations.

\begin{tabular}{|c|c|c|c|}
\hline Life Cycle & $\begin{array}{l}\text { Vocabulary } \\
\text { Words }\end{array}$ & Frequency & $\begin{array}{l}\text { Total for This } \\
\text { Life Cycle }\end{array}$ \\
\hline \multirow{8}{*}{ Sea Turtle } & Egg & 4 & \multirow{8}{*}{15} \\
\hline & Hatchling & 3 & \\
\hline & Plastron & 3 & \\
\hline & Incubation & 2 & \\
\hline & Sea Turtle & 2 & \\
\hline & Carapace & 1 & \\
\hline & Submerged & 0 & \\
\hline & Reptile & 0 & \\
\hline \multirow{8}{*}{ Bean Plant } & Seedling & 6 & \multirow{8}{*}{28} \\
\hline & Sprout & 5 & \\
\hline & Seed or Seed Coat & 5 & \\
\hline & Pollinate & 4 & \\
\hline & Pod & 3 & \\
\hline & Bean Plant & 3 & \\
\hline & Soil & 2 & \\
\hline & Germinate & 0 & \\
\hline \multirow{8}{*}{ Dragonfly } & Insect & 7 & \multirow{8}{*}{27} \\
\hline & Dragonfly & 7 & \\
\hline & Predator & 4 & \\
\hline & Hover & 4 & \\
\hline & Nymph & 3 & \\
\hline & Molt & 1 & \\
\hline & Larva & 1 & \\
\hline & Antenna & 0 & \\
\hline \multirow{8}{*}{ Horse } & Foal & 6 & \multirow{8}{*}{16} \\
\hline & Mammal & 5 & \\
\hline & Horse & 2 & \\
\hline & Harness & 2 & \\
\hline & Mare & 1 & \\
\hline & Stallion & 0 & \\
\hline & Muzzle & 0 & \\
\hline & Offspring & 0 & \\
\hline
\end{tabular}

with farming of soy beans, and personal experience with dragonflies, they depicted them in their work more frequently. Students were able to show retention of vocabulary concepts through a creative product rather than a traditional paper and pencil test.
Figures 2-5 feature selected parts of student products to show how students depicted components of the life cycles. All of the items shown here were expressly labeled by students with the vocabulary words related to these components being highlighted. Students also verbally explained their work to the teacher (first author of this article). For each example, we
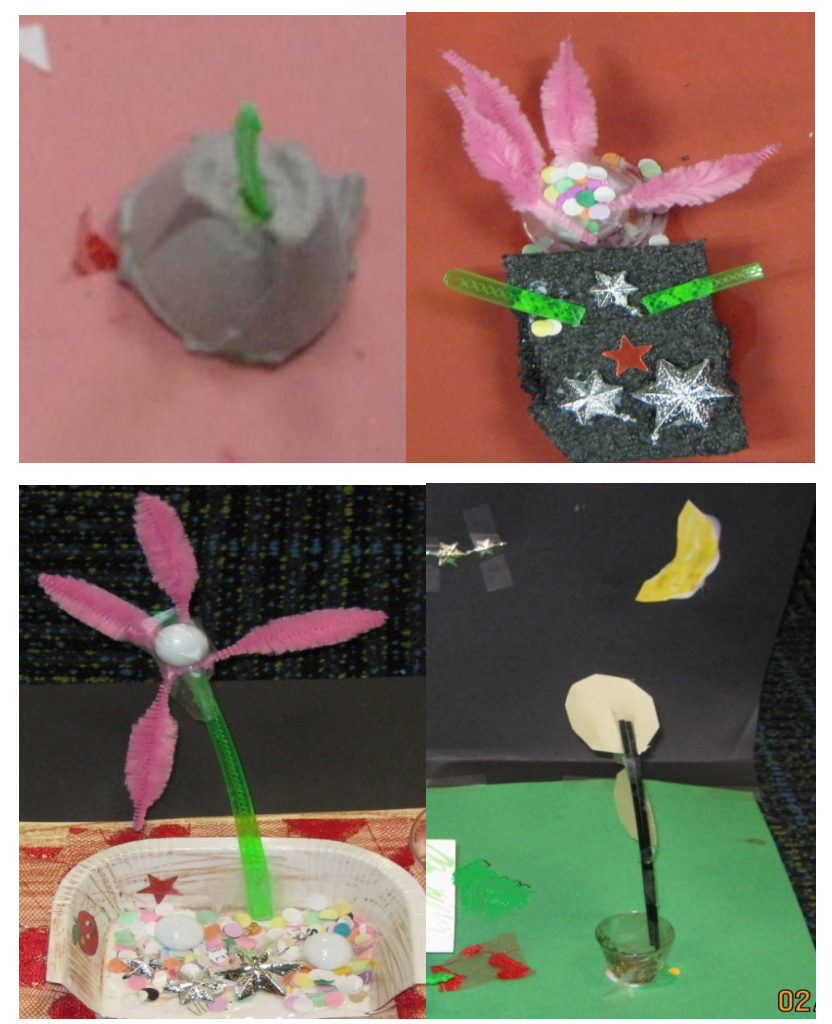

Figure 2.

Student's products related to the bean plant life cycle.
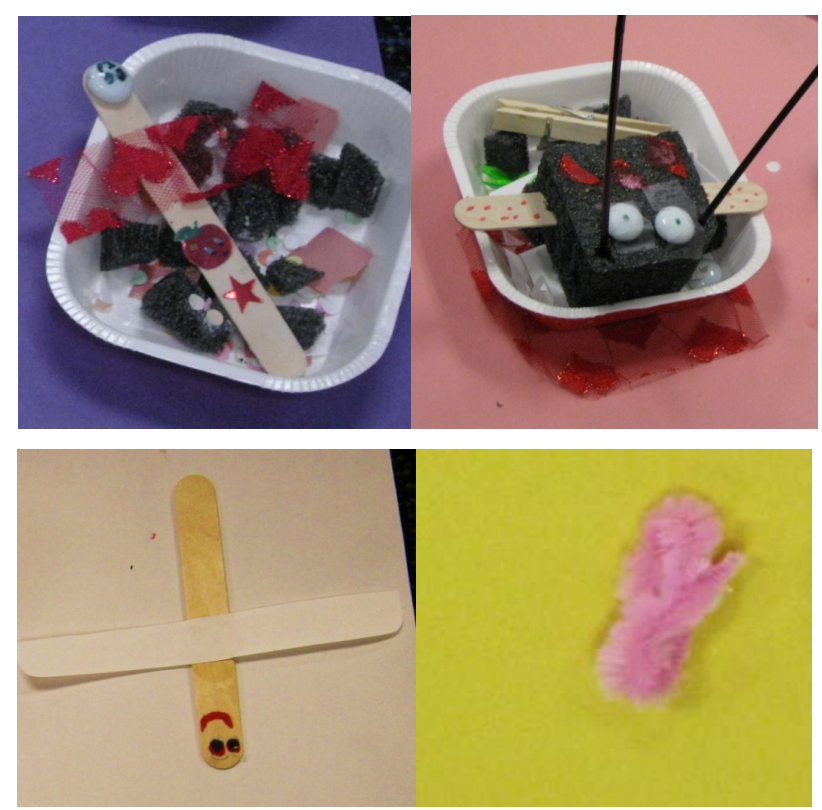

Figure 3.

Student's work related to the dragonfly life cycle. 

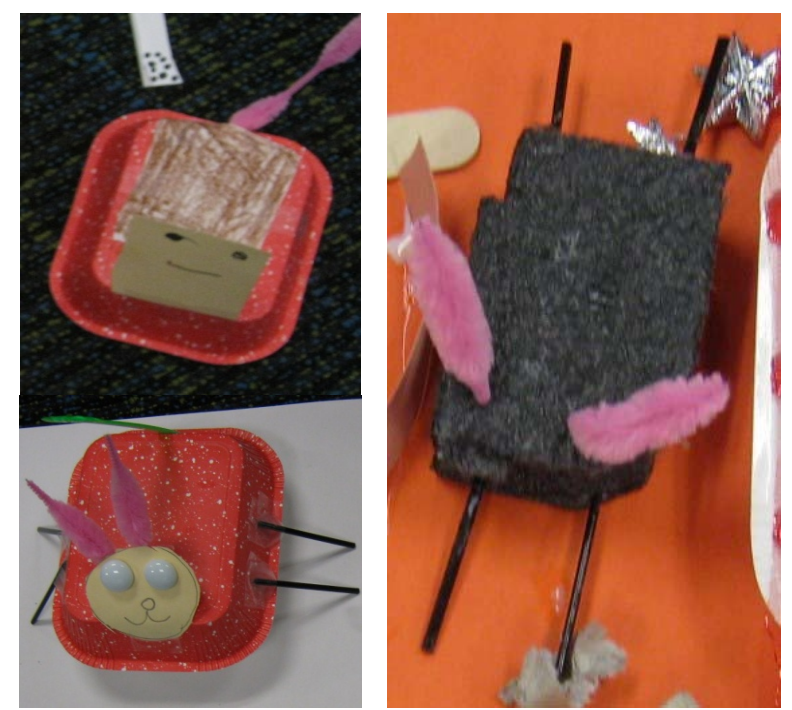

Figure 4.

Three different students' foals from the horse life cycle.

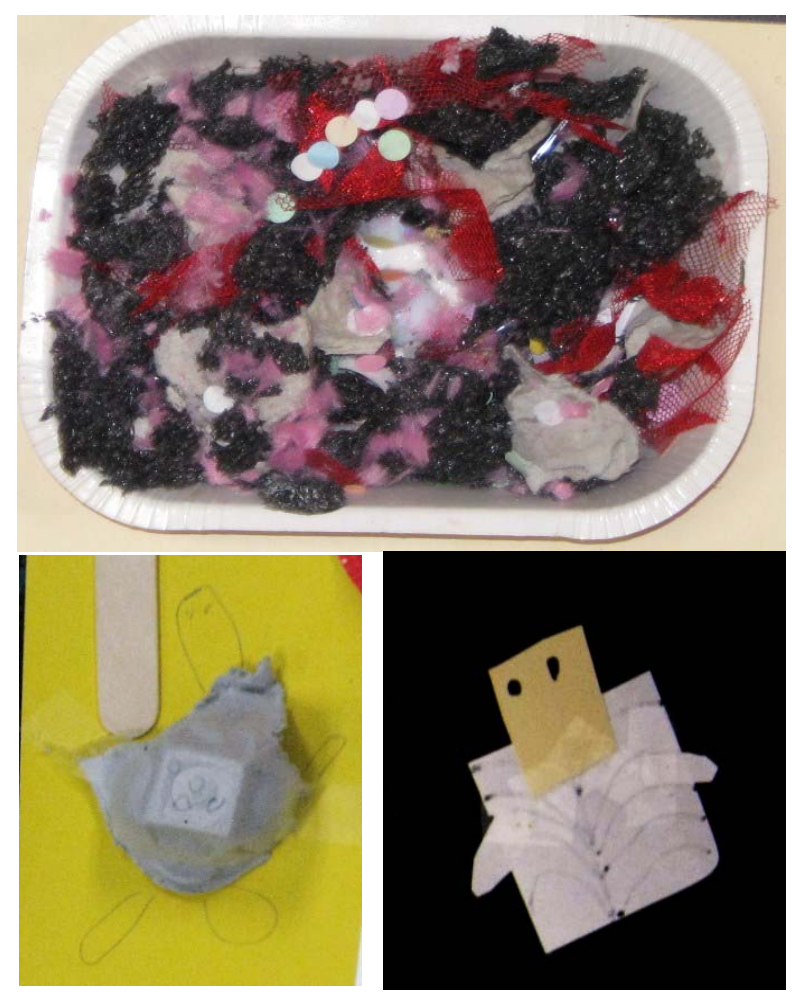

Figure 5.

Different students' constructions of parts of the sea turtle life cycle.

discuss the creative strengths exhibited by the student. Figure 2 shows parts of student products related to the bean plant life cycle. The sprout was made with a cut portion of the green plastic palm tree drink stirrer thrust into the gray egg carton cup that represented the soil, a creative idea because the student modified the given pieces rather than using them as a whole (creative strength of breaking boundaries).

The top right image of Figure $\mathbf{2}$ shows a seedling that has matured enough to develop a flower. The cut pieces of green plastic are the leaves and the pink fuzzy bumpy chenille stick was used to make an appealing flower (creative strength of richness of imagery). The student showed pollination and seed development with the multicolored confetti paper punches. The stars are seeds from the flower that are falling to the ground and starting to sprout. This product shows a lot of detail (creative strength of elaboration), tells the story of plant's reproduction (creative strength of story-telling articulateness), and shows motion (creative strength of movement) with the falling seeds.

The bottom left image of Figure 2 shows a flowering bean plant in a container with soil. The soil shows details of various components: rocks are represented by the paper punches while stars symbolize the soil (creative strength of elaboration). The apple sticker signifies the idea of a garden with edible food while the red heart netting symbolically protects the garden with love (creative strength of abstract thinking).

The final image in Figure 2 at the bottom right shows several unusual aspects. First, the student made a three-dimensional scene by taping the black night sky backdrop to the green ground (creative strength of three-dimensionality). No other students made a three dimensional backdrop, so this was a unique idea (creative strength of originality). Then the student contrasted the beauty of a newly-opened white flower with the trashy paper-punch litter in the flower pot cup and as bits of heart netting on the ground (creative strength of abstract thinking).

Figure 3 shows images of student work related to the dragonfly life cycle or insects. The upper left image shows a dragonfly laying eggs. The dragonfly has red netted wings and is hovering over the eggs. A white flat marble was used as the head and contains eyes. The student cut and altered materials to make the dragonfly and eggs (creative strength of breaking boundaries), producing many parts to show detail (creative strength of elaboration) in this scene of a female dragonfly hovering over her eggs (creative strength of storytelling articulateness). The top right image shows the parts of an insect that were studied at the time of the dragonfly life cycle. The student included the three-part body of head, thorax and abdomen, the antennae, wings, and spotted pattern of a ladybug (creative strength of elaboration). In contrast, the lower left image of a dragonfly shows little detail or elaboration, but it shows the creative strength of emotional expressiveness through the smile. The last image on the bottom right is a dragonfly nymph that indicates the student's content knowledge of the wingless form of this larva.

Figure 4 shows three different ways students depicted a foal of the horse life cycle. The upper left image shows a young horse with a pink chenille tail and red-brown body colored with crayon (creative strength of elaboration). The right image shows black stirrer legs, pink chenille ears, and a connected string of silver stars for a tail on the black foam body (creative strength of elaboration). The last image on the lower left shows facial features, including a smile, in addition of legs and tail (creative strength of emotional expressiveness).

Figure 5 illustrates images from the sea turtle life cycle. The upper left image is of a sea turtle nest. The paper punches are eggs, the cut pieces of black foam and red netting are sand, and the gray pieces of egg carton are the sea turtles concealing the nest. This image shows several layers inside of the nest (creative strength of internal visualization). The pink fuzz is fur from a predator that was seeking to uncover and eat the eggs (creative strength of storytelling articulateness). The bottom left 
image shows a turtle's carapace with concentric circle designs (creative strength of elaboration) while the final image shows the plastron on the underside of a sea turtle (creative strength of an unusual perspective). The plastron in the drawing also shows attention to detail, as the suture lines are visible (creative strength of elaboration).

\section{Misconceptions}

An open-ended culminating project like the one described in this article is a good place to examine misconceptions in student thinking. Although none were detected in this project, several research studies indicate that children have misconceptions about animal life cycles that they eventually outgrow with appropriate instruction. For example, Nguyen and Rosengren (2004), in surveying parents concerning their children's biological knowledge of life cycles, found fewer misconceptions in 5 to 6 year olds than 3 to 4 year olds, indicating that misconceptions are open to change and are eventually replaced with accurate facts. For instance, some younger children thought that babies grew from seeds like plants whereas older students knew that babies grew inside their mothers' bodies and had characteristics of their parents. Similarly, Hickling and Gelman (1995) reported that most children understood before age five that plants grow from seeds. Another common misconception among first graders reported by teachers was the belief that insects were not animals because they are not furry, four-legged creatures (Pine, Messer \& St. John, 2010). An emphasis on scientific classification of animals into different classes such as mammals, reptiles, and insects helps students understand that all animals are not mammals. In this study, the teacher presented three life cycles from these different classes of animals, drawing student attention to the fact that dragonflies, as insects, are indeed a type of animal.

\section{Conclusion}

Students were able to evidence their content knowledge and vocabulary acquisition related to animal life cycles through this activity. They incorporated 25 different words related to the life cycles as was shown in Table 3 and showed many different parts of the life cycles. This level of vocabulary acquisition is particularly interesting, given the fact that students did not study or review vocabulary for this assessment-the results indicate student learning solely from the lessons. Additionally, students were able to demonstrate and practice creative strengths and problem-solving abilities through this exercise. They especially exhibited elaboration, breaking of boundaries, storytelling articulateness, abstract thought, emotional expressiveness, and unusual perspectives. Although the teacher focused more of her instruction regarding creativity on adding details and using materials in different ways, students spontaneously displayed other strengths. The relaxed productive atmosphere produced in the classroom by addressing creative thinking skills promoted a safe environment where risk-taking was encouraged. Therefore, students naturally evidenced other creative traits (Cremin, Burnard, \& Craft, 2006). This situation fits with Lin's (2009, 2011) triangular model for creative pedagogy of "creative teaching," "teaching for creativity," and "creative learning" at each of the three vertices. Teaching creatively involves "using imaginative approaches to make learning more interesting and effective" (NACCCE, 1999: p. 89): the teacher provided an exciting activity with interesting recycled and craft items for students to re-envision as life cycle parts. The "teaching for creativity" aspects highlighted identifying and developing learner capabilities as the teacher gave instruction on elaboration, breaking boundaries, and generating original ideas. By standing back, allowing students to take responsibility for their creative work, by encouraging the students' curiosity, questioning and decision-making, the teacher facilitated "creative learning” component of Lin's triangular model.

In future studies, this activity could be repeated several times so that students could become more aware of all of the creative strengths and practice these skills. If a teacher used this type of activity for weekly practice of content, both academic content and creativity skills might be practiced, allowing students to make growth in multiple areas. The vocabulary and concepts students depict in their work also provide a useful assessment of information being learned.

\section{REFERENCES}

Assessment \& Teaching of 21st Century Skills (2012). What are 21st century skills? URL (last checked 28 May 2012).

http://atc21s.org/index.php/about/what-are-21st-century-skills/

Center for 21st Century Skills (2012). Redesigning education. URL (last checked 28 May 2012). http://www.skills21.org/

Center on Educational Policy (2009). Compendium of key studies of the no child left behind act. Washington DC, WA: Center on Educational Policy.

Cremin, T., Burnard, P., \& Craft, A. (2006). Pedagogy and possibility thinking in the early years. International Journal of Thinking Skills and Creativity, 1, 108-119. doi:10.1016/j.tsc.2006.07.001

Davis, G. A., Rimm, S. B., \& Siegle, D. (2011). Education of the gifted and talented (6th ed.). Boston, MA: Pearson.

Education Connection (2012). Center for $21^{\text {st }}$ century skills at education connection. URL (last checked 25 May 2012).

http://www.skills21.org/

Guilford, J. P. (1967). The nature of human intelligence. New York, NY: McGraw-Hill Book Co.

Guilford, J. P. (1977). Way beyond the IQ. Great Neck, NY: Creative Synergistic Associates.

Guilford, J. P., \& Hoepfner, R. (1971). The Analysis of intelligence. New York, NY: McGraw-Hill Book Co.

Hamilton, L. S., Stecher, B. M., Marsh, J. A., McCombs, J. S., Robyn, A., Russell, J. L., Naftel, S., \& Barney, H. (2007). Standards-based accountability under no child left behind: Experiences of teachers and administrators in three states. Santa Monica, CA: Rand Corporation.

Hickling, A. K., \& Gelman, S. A. (1995). How does your garden grow? Early conceptualization of seeds and their place in plant growth cycle. Child Development, 66, 856-876. doi:10.2307/1131955

Lin, Y.-S. (2009). Teacher and pupil responses to a creative pedagogy-Case studies of two primary classes in Taiwan. Unpublished Doctoral Thesis, Exeter: University of Exeter.

Lin, Y.-S. (2011). Fostering creativity through education-A conceptual framework of creative pedagogy. Creative Education, 2, 149155.

Michalko, M. (2001). Cracking creativity: The secrets of creative genius. Berkeley, CA: Ten Speed Press.

National Advisory Committee on Creative and Cultural Education (1999). All our futures: Creativity, culture \& education. Sudbury, Suffolk: Department for Education and Employment.

Nguyen, S. P., \& Rosengren, K. S. (2004). Parental reports of children's biological knowledge and misconceptions. International Journal of Behavioral Development, 28, 411-420. doi:10.1080/01650250444000108

Partnership for 21st Century Skills (2011). A framework for 21st century learning. URL (last checked 25 May 2012). http://www.p21.org/home

Pine, K., Messer, D., \& St. John, K. (2010). Children’s misconceptions 
in primary science: A survey of teachers' views. Research in Science \& Technological Education, 19, 79-96.

doi:10.1080/02635140120046240

Rule, A. C., Alkouri, Z. A., Criswell, S. J., Evans, J. L., Hileman Webb, A. N., Parpucu, H., Ruan, B., Van Meeteren, B. D., Uhlenberg, J., Vasileva, O. S., \& Zhbanova, K. S. (2012). Practicing creative thinking skills by making creative products related to economic issues. Social Studies Research and Practice, 7.

Rule, A. C., Zhbanova, K., Hileman Webb, A., Evans, J., Schneider, J. S., Parpucu, H., Logan, S., Van Meeteren, B., Alkouri, Z., \& Ruan B.
(2011). Creative product problem-solving game: Exploring Torrance's creative strengths by making an object from a set of given materials. ERIC Document Reproduction Service No. ED527045. Washington DC: Educational Resources Information Center.

Torrance, E. P., Ball, O. E., \& Safter, H. T. (1992). Torrance tests of creative thinking: Streamlined scoring guide. Figural A and B. Bensenville, IL: Scholastic Testing Service.

Webb, A. N., \& Rule, A. C. (2012). Developing second graders' creativity through literacy-science integrated lessons on lifecycles. Early Childhood Education Journal. doi:10.1007/s10643-012-0532-y 